\title{
Notas Relativas a los Corrales de la Ciudad de México
}

\author{
1626 - 1641
}

QE han hecho varias conjeturas con el fin de determinar la $\checkmark$ fecha desde la cual existía en la ciudad de México el corral que explotaban los religiosos hipólitos en provecho de los pacientes del Hospital Real de Indios. Luis González Obregón data su origen desde antes de 1673:

En efecto, antes del año de 1700, México contaba ya con un teatro en forma, situado dentro del Hospital Real, cerca de su camposanto. El teatro existía antes de $1673 \ldots$ (1)

Francisco Pimentel cree que ya funcionaba este teatro a mediados del siglo XVII:

A mediados del mismo siglo XVII, había en México, un teatro de madera, situado dentro del Hospital Real:

se incendió é Enero 19 de 1722. (2)

Manuel Mañón indica que dicho teatro fué construído hacia los años de 1671 a 1672:

Dicho primer teatro fué el del Hospital Real de Naturales, construído en el claustro del mismo hospital hacia los años de 1671 a 1672, aun cuando su Cédula de creación se remontaba al año de 1553 . (3) 
Rodolfo Usigli, quien también ha escrito recientemente sobre este asunto, opina que el edificio no se usó antes de la segunda mitad del siglo, $y$ acaso de su segundo decenio.

Aunque las cédulas del hospital datan de 1553 , no se precisa la fecha en que haya comenzado a funcionar este teatro. Fué indudablemente en el siglo XVII, y no en sus comienzos, aunque se pretende que en 1673 -fecha que ofrece el documento de un primer elencollevaba ya muchos años de existencia. Juzgando por las acotaciones de los diarios de noticias que he dejado insertas, creo que este primer coliseo data de la segunda mitad del siglo, y acaso de su segundo decenio, época en la que muestra el teatro una orientación hacia cierto carácter estrictamente profesional. (4)

Pero ya se representaban piezas en el corral del Hospital Real unos veintitrés años antes de 1650, la fecha más temprana señalada por los escritores citados, y además había dos corrales en la ciudad de México (5). El cabildo municipal, después de haber tratado de la fiesta del Sántísimo Sacramento, se quejó en las actas del 17 de abril de 1626 de no tener aposento capaz para ver las comedias. Por lo tanto, se resolvió nombrar una comisión que suplicaría al virrey que se sirviese señalar en los dos corrales sitio para el ayuntamiento:

La ciudad dice que por cuanto la esperiencia ha mostrado la insidencia con que la ciudad está en los corrales de representaciones de comedias por no tener aposento capaz señalado en que asista como se usa y le tiene madrid sevilla y las demás ciudades despaña y esta que es cabeza deste reino es justo le tenga con todo ornato y desencia donde puedan estar los regidores cómodamente de que resultará el escusar inconvenientes y para que tenga efecto acuerda de conformidad que el señor procurador mayor $y$ don fernando carrillo en nombre desta ciudad besen la mano a su excelencia y le supliquen se sirva de señalar en los dos corrales a la ciudad sitio capaz donde vean las comedias pues es cosa usada en todas las ciudades y señalándolos los dispongan $y$ hagan aderesar con toda desencia a costa de propios poniéndole llaves y ordenando a los porteros 
tengan los dias de comedias las bancas y alfombras para que asista el señor corregidor y regidores como ciudad. (6)

En la junta del 17 de marzo de 1627, casi un año más tarde, se leyó un acuerdo que incorporó las sugestiones propuestas en el mes de enero. Se habían discutido las inconveniencias sufridas en el pasado por la falta de sitio acomodado en los corrales (el plural indica de nuevo que aún quedaban en uso por lo menos dos corrales), y, determinados a remediar la situación, los regidores habían dado a los señores Melchor de Vera y Cristóbal de Molina el cargo de tratar y señalar dos aposentos. Estos dieron a conocer que habían concertado con el mayordomo del Hospital Real para el cabildo los aposentos número cinco y seis de mano derecha. Por dicho sitio la ciudad se comprometió a pagar anualmente sesenta pesos:

... cuando van a las comedias los caballeros regidores no hallan aposentos en lugar desente como es justo y se murmura entre los cuidadanos (sic) que era causa que se debía atender disponiendo los corrales desta ciudad aposentos y lugar capaz y decentes para que todos los días de fiesta pueda ir esta ciudad y caballeros regidorés della y tener aposentos donde ver las comedias... En cumplimiento de lo que vuesa señoría manda por acuerdo de esta otra parte se ha hecho la diligencia con pedro de peralta mayordomo del hospital real de los indios donde está el corral de comedias y está comunicado y concertado que dé y señale para esta ciudad dos aposentos del dicho corral número cinco y seis de mano derecha dándole por vía de limosna sesenta pesos cada año de los propios desta ciudad con condición que este concierto haya de confirmar su excelencia por el patronasgo real del dicho hospital y por la firmeza que tendrá para siempre jamás así para esta ciudad como para el mayordomo que es o: fuere del dicho hospital lo cual ha de pedir el procurador mayor desta ciudad informando a su exeleneia que todas las ciudades de su magestad tienen el dicho asiento señalado... (7)

El 9 de abril del mismo año el ayuntamiento volvió a deliberar sobre la proposición. Se descubre que los sesenta 
pesos serían pagados por tercios y que los dos aposentos se habían convertido en uno, ya bien adornado y equipado con puerta. El cabildo acordó pagar a Pedro de Peralta, mayordomo del Hospital Real, el aderezo del aposento y le confió la tarea de llevar allí alfombras y sillas los días de fiesta en que se representaran obras dramáticas. Por dicho servicio éste recibiría anualmente veinticuatro pesos de oro común pagados por tercios, pero se le mandó que no permitiese entrar a ninguna persona que no fuera caballero del cabildo:

... que en conformidad de la dicha eseriptura se había aderezado el dicho aposento haciéndolo de dos $\mathrm{y}$ echándole puerta y llave de lova $\mathrm{y}$ questo lo habia hecho el dicho pedro de peralta... Visto por la ciudad aprobó la dicha escriptura y mandó quel señor don pedro de la barrera la lleve a su exelencia para que se sirva de confirmarla y se pague a pedro de peralta lo que pareciere haber gastado en el dicho aderezo de los propios y el mayordomo en esta parte cumpla lo que libran los dichos señores tesoreros y cualquier dellos y por cuanto para aderezar el dicho aposento es necesario llevar todos los días de comedias alfombras y sillas se encarga el hacerlo como lo ha hecho hasta aquí a antonio gonzalez portero del cabildo y por el trabajo que en ello ha de tener se le señalan de salario en cada un año veinte y cuatro pesos de oro común pagados de los dichos propios por sus tercios cumplidos y se le notifique no dé la llave del dicho aposento ni consienta entre en él a ver comedias sino fuere caballero deste cabildo para que no se le pagara el dicho salario y será castigado el cual dicho salario le dé por la costa y gasto que ha de tener en llevar y traer las alfombras y sillas. (8)

Este concierto siguió obrando durante algún tiempo, porque el 29 de enero de 1629 se leyó una petición del Hospital Real de Indios en la cual se rogó que la ciudad pagase cien pesos, cuarenta debidos desde el año anterior. (9)

El 3 de septiembre de 1640 se llamó la atención al ca- . bildo del mal estado de los aposentos en el corral del coliseo:

El señor leandro de gatica propuso la indesencia de los aposentos de la comedia en el corral del coliseo y.que están muy bajos que se provea sobrello. $\mathrm{Y}$ se 
acordó que el señor leandro de gatica y don fernando carrillo con intervención del señor don juan de cervantes vean los aposentos y los dispongan lo más decentemente que se pueda y se adornen. (10)

Puede ser que este coliseo fuera acaso el segundo de los dos corrales mencionados en las actas del 17 de abril de 1626, visto que las alusiones al otro indicaron por lo general que era propiedad del Hospital Real.

Entre tanto, algunos capitulares habían tomado la costumbre de invitar a sus amigos a ocupar sillas en el aposento, $\mathrm{y}$, de resultas de las incomodidades a los demás, el procurador mayor suplicó el 19 de septiembre de 1641 que no consintieran que entrasen otros hasta que estuviera dentro todo el cabildo:

El señor procurador mayor por petición dijo que sin embargo de los acuerdos de cabildo para que en el aposento de comedias no se sienten más de los capitulares escribano mayor de cabildo $y$ su teniente entran otras personas por convidados que llevan los capitulares dándoles el primer lugar y suplica de nuevo que no entre otra ninguna persona ni los capitulares los conviden imponiéndoles pena y que los porteros asistan y no den la llave ni consientan entre ninguna persona hasta que la ciudad esté dentro... (11)

\section{HARVEY L. JoHNSON, Northwestern University.}

(1).-México viejo. México, 1900, p. 337.

(2).-Obras completas. México, 1903, IV, p. 144.

(3).-Historia del Teatro Principal de México. México, 1932, p. 15.

(4).-México en el teatro. México, 1932, p. 47.

(5).-Arias de Villalobos en su "Canto intitulado Mercurio", poema que trata de la ciudad de México desde la conquista hasta el año 1623, se refirió a dos teatros que solían representar comedias de Castilla. Hay también otras referencias, de los tres primetos años del siglo XVII, que prueban la existencia de dos casas de comedias en la capital. José J. Rojas Garcidueñas, El teatro de Nueva España en el siglo XVI, México, 1935, p. 121. 
(6).-Actas antiguas de cabildo. México, 1907, XXIV, lib. xxvi, p. 34 .

(7),-lbid., p. 102

(8).-1bid., p. 107.

(9).-Ibid., lib. xxvii, p. 44.

(10).-Ibid., XXVI, lib. xxxii, p. 112.

(11).-1bid., p. 245 . 